\title{
Controlling the formation and structure of nanoparticle superlattices through surface ligand behavior
}

\author{
Marco A.L. Cordeiro ${ }^{*} \dagger$, Edson R. Leite $¥$, Eric A. Stach ${ }^{\dagger}$. \\ $\uparrow$ Center for Functional Nanomaterials, Brookhaven National Laboratory, Upton, New York 11973, United States. \\ Department of Chemistry, Federal University of Sao Carlos, 13565-905 Sao Carlos, SP, Brazil
}

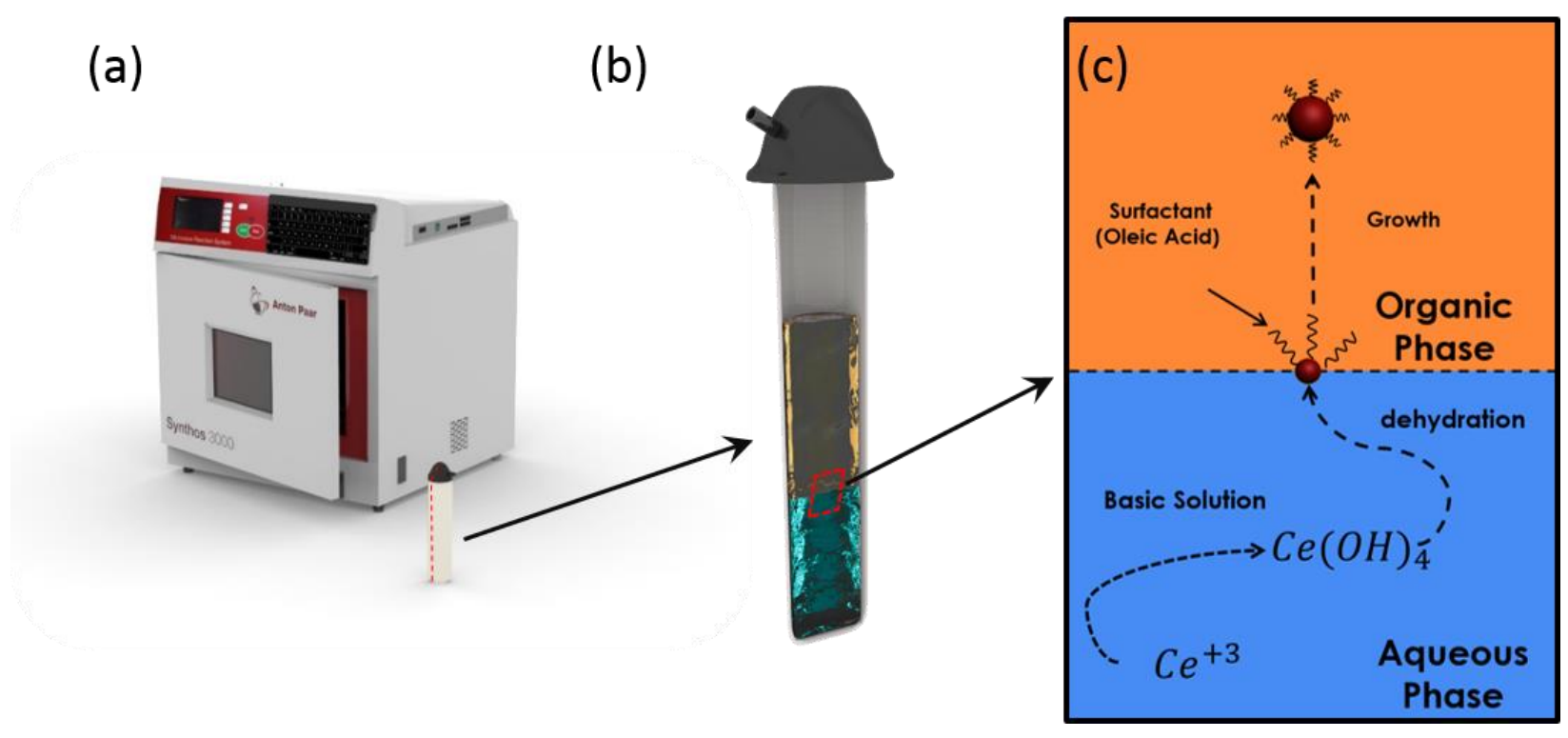

Figure S1. Scheme of the synthesis procedure for the $\mathrm{CeO}_{2}$ nanoparticles synthesis using a twophase hydrothermal method in microwave oven. (a) Microwave oven; (b) Teflon-lined autoclave; (c) Synthesis mechanisms. 
(a)

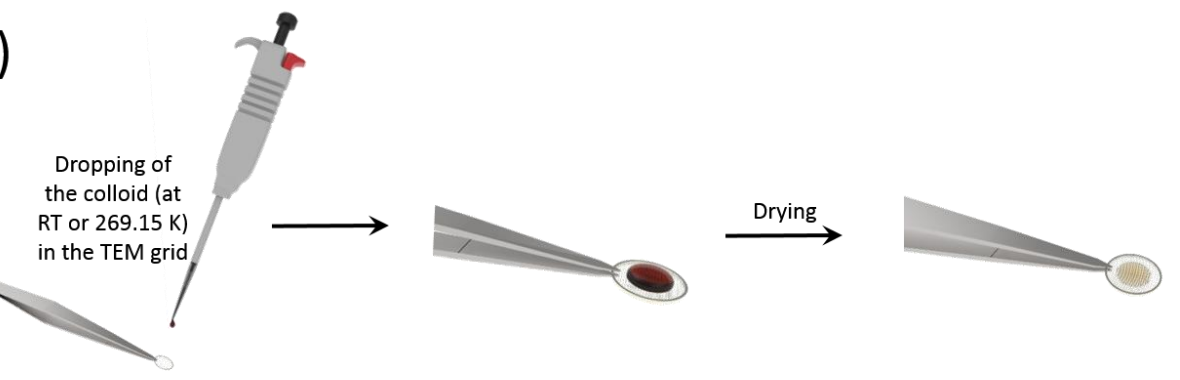

(b)

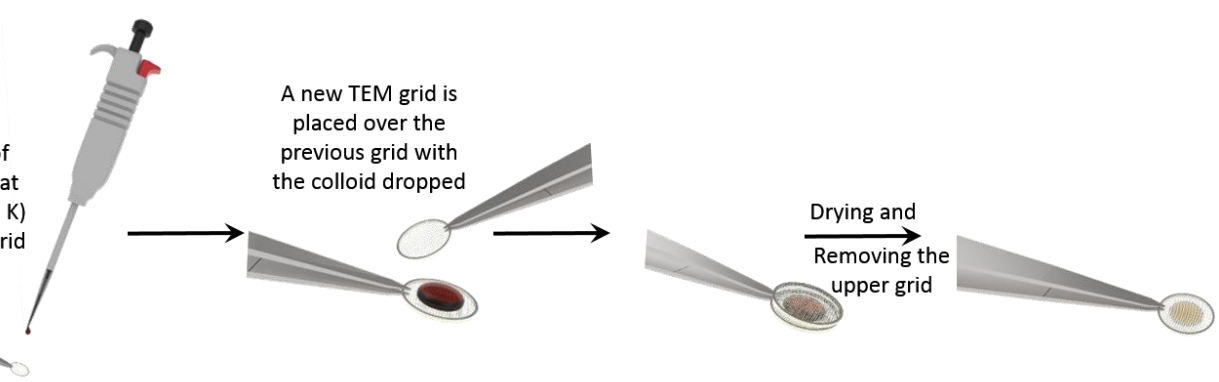

(c)

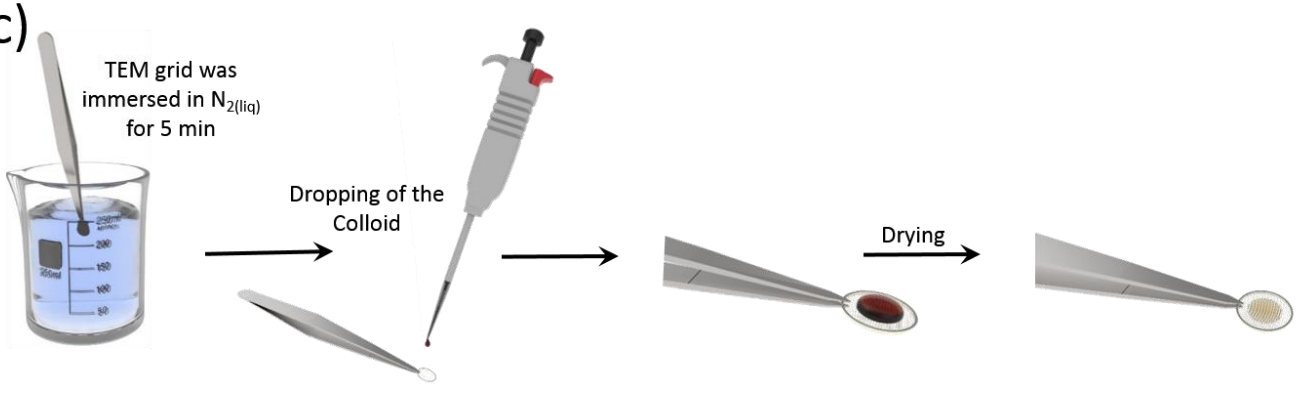

(d)

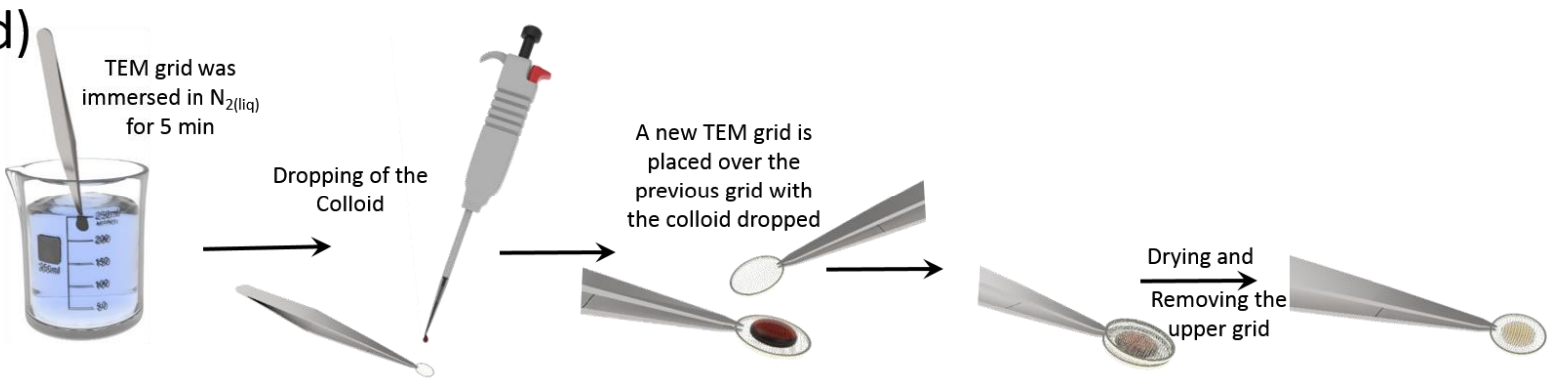

Figure S2. (a)-(d) Deposition methods utilized in this study. 


\section{Estimation of the temperature of the $\mathrm{CeO}_{2}$ colloid drop on TEM grid after immersed in}

$$
\mathbf{N}_{2(\text { liq) }}
$$

For the calculation of the temperature variation of the toluene based $\mathrm{CeO}_{2}$ colloid drop, it was assumed a transient heat conduction based on lumped system analysis. ${ }^{1}$ The applicability of this method can be ensured by the analysis of the Biot number $(B i)$, which is the ratio of the internal resistance of the body to heat conduction to its external resistance to heat convection. ${ }^{1}$ A small Biot number $(B i<0.1)$ indicates a lower resistance to heat conduction, i.e. a small temperature gradient within the body. Biot number can be calculated by:

$B i=\frac{h V}{k A_{s}}$

where is $h$ the heat transfer coefficient, $V$ is the colloid drop volume, $A_{s}$ is the superficial area of the colloid drop and $k$ the thermal conductivity. Assuming the properties of the toluene drop $(V=$ $\left.5 \times 10^{-9} l, A_{s}=2.02 \times 10^{-5} \mathrm{~m}^{2}, \quad h=30 \mathrm{~W} / \mathrm{m}^{2} \mathrm{~K}, \quad k=15 \mathrm{~W} / \mathrm{m} \mathrm{K}\right)$, the Biot number is $0.49 \times 10^{-3}(\ll 0.1)$. Then, the temperature of the drop according to the time can be determined:

$T(t)=e^{-\frac{h A_{s} t}{\rho V c_{p}}}\left(T_{i}-T_{e}\right)+T_{e}$

where $t$ is the time, $\rho$ is the density, $c_{p}$ is the specific heat, $T_{i}$ is the drop temperature and $T_{e}$ is the external temperature. Figure S3 shows the temperature of the toluene drop by time immediately after the contact with the cooled grid.

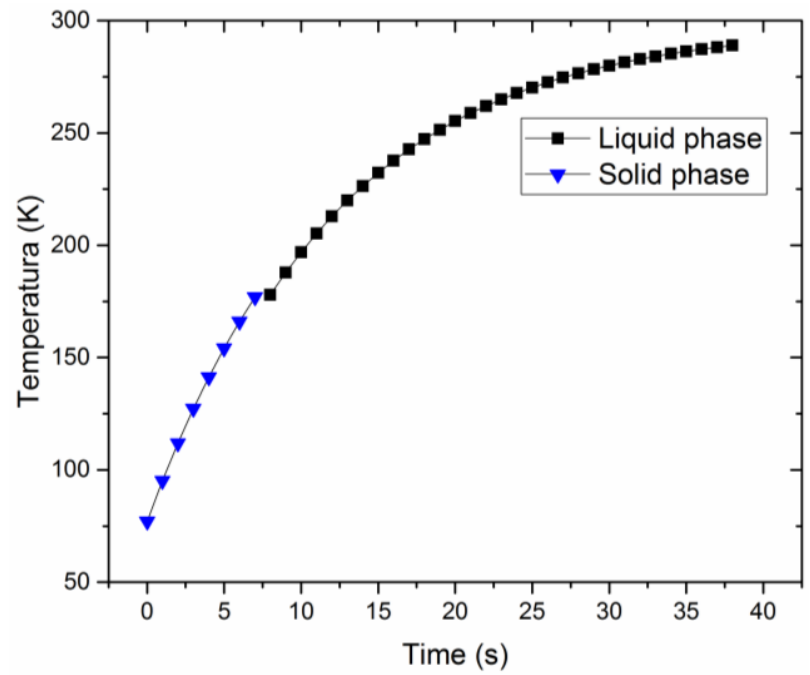

Figure S3. Temperature of the NP colloid by temperature immediately after the contact of one drop with the cooled grid at $77 \mathrm{k}$.

In all experiments, the deposited drop of $\mathrm{CeO}_{2}$ colloid immediately freezes after the contact with the nickel grid, inferring the colloid temperature is between $77 \mathrm{~K}$ and $178 \mathrm{~K}$. Just after melting start, the evaporation of the drop happens completely within $5 \mathrm{~s}$, which expected gap of temperature for these samples is $178-212 \mathrm{~K}$. 

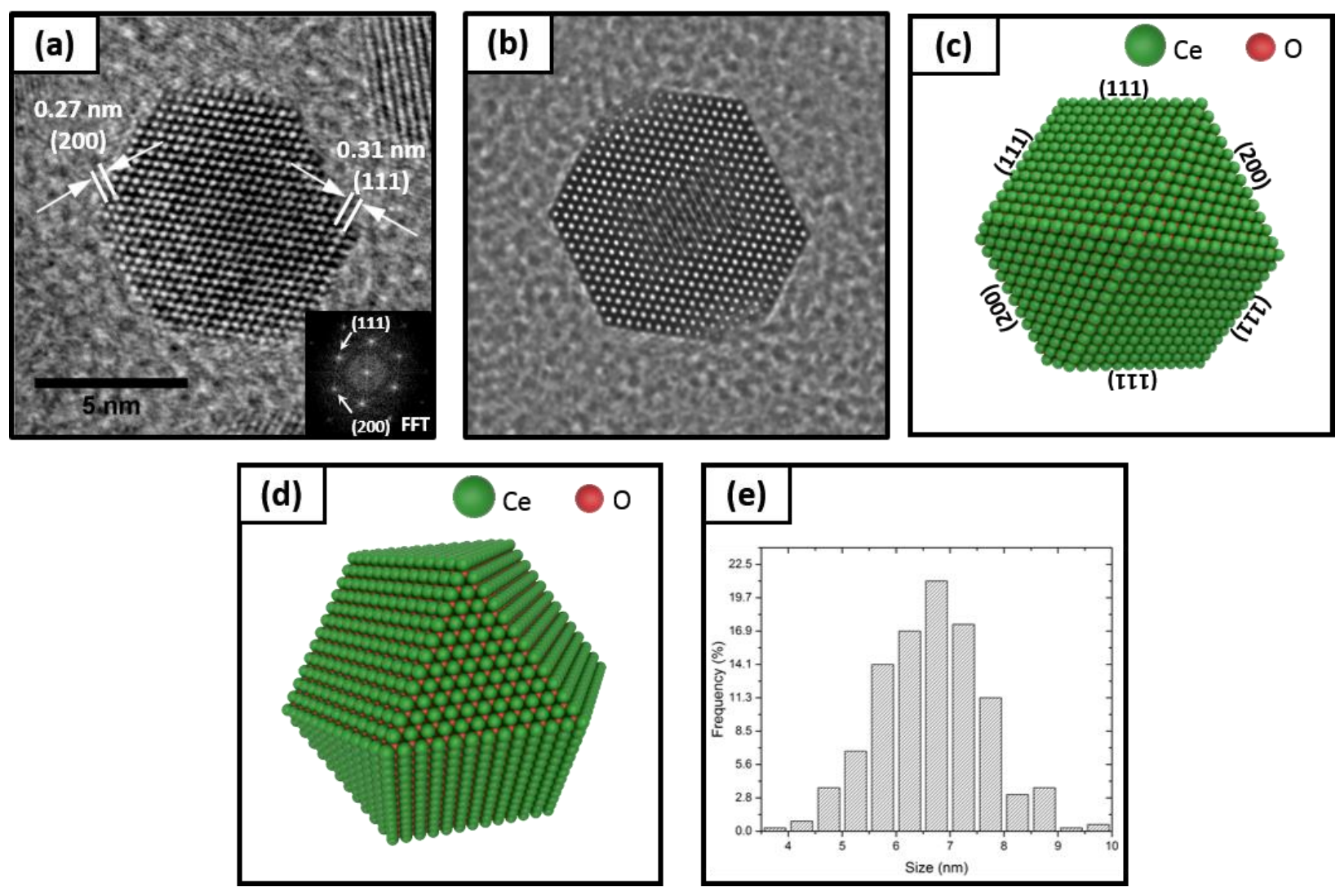

Figure S4. (a) Experimental HRTEM image of a polyhedral $\mathrm{CeO}_{2} \mathrm{NP}$ and (b) image simulation; (c) input used in the simulation and (d) the same input in a perspective view. (e) Size distribution of polyhedral $\mathrm{CeO}_{2} \mathrm{NPs}$ by frequency. 

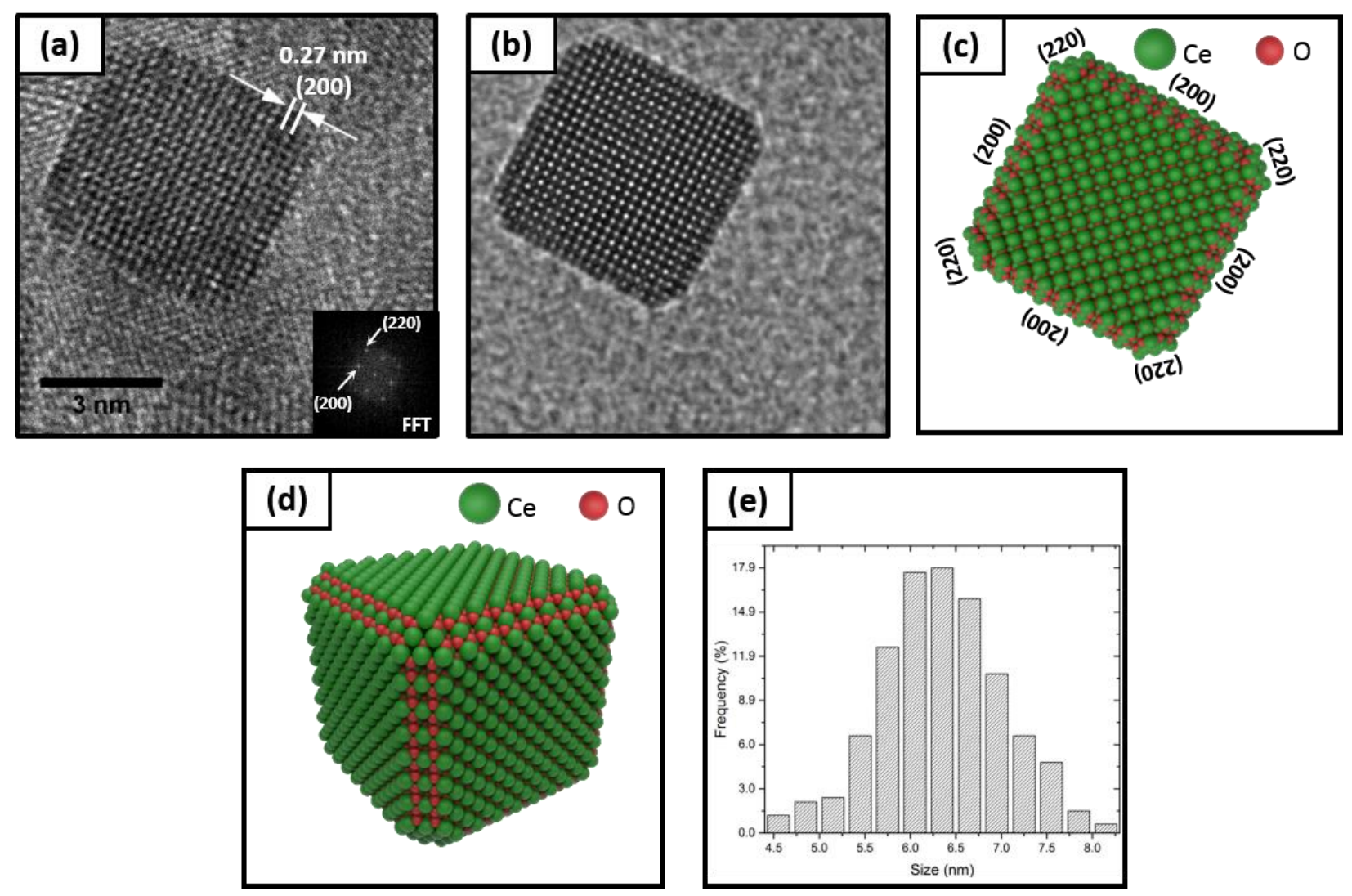

Figure S5. (a) Experimental HRTEM image of a cubic $\mathrm{CeO}_{2} \mathrm{NP}$ and (b) image simulation; (c) input used in the simulation and (d) the same input in a perspective view. (e) Cubic $\mathrm{CeO}_{2} \mathrm{NPs}$ sizes distribution by frequency. 


\section{Same Areas}
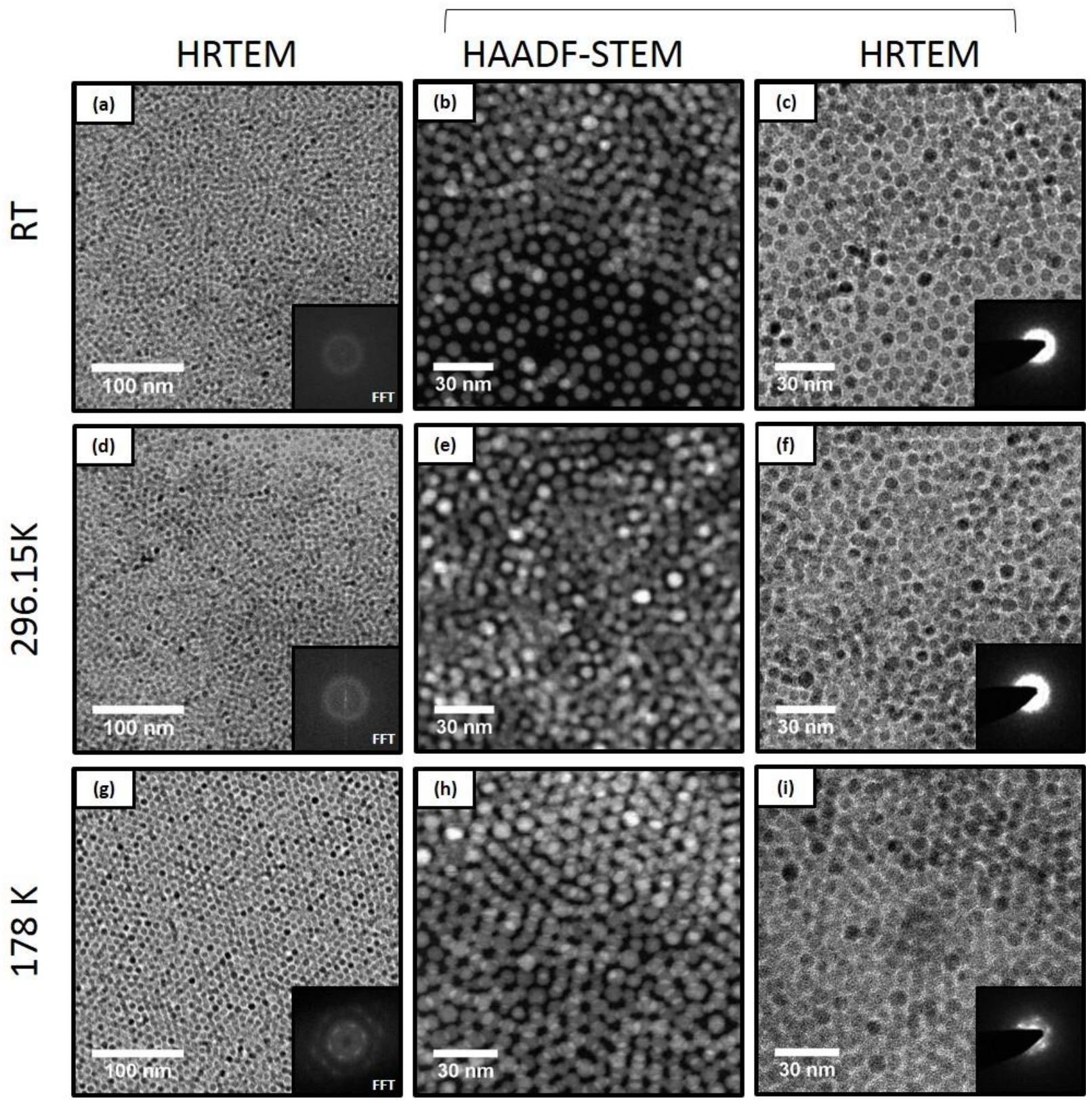

Figure S6. Electron microscopy images of polyhedral $\mathrm{CeO}_{2} \mathrm{NPs}$ prepared by normal deposition. (a)-(c) RT, (d)-(f) $269.15 \mathrm{~K}$ and (g)-(i) $178 \mathrm{~K}$. 


\section{Same Areas}
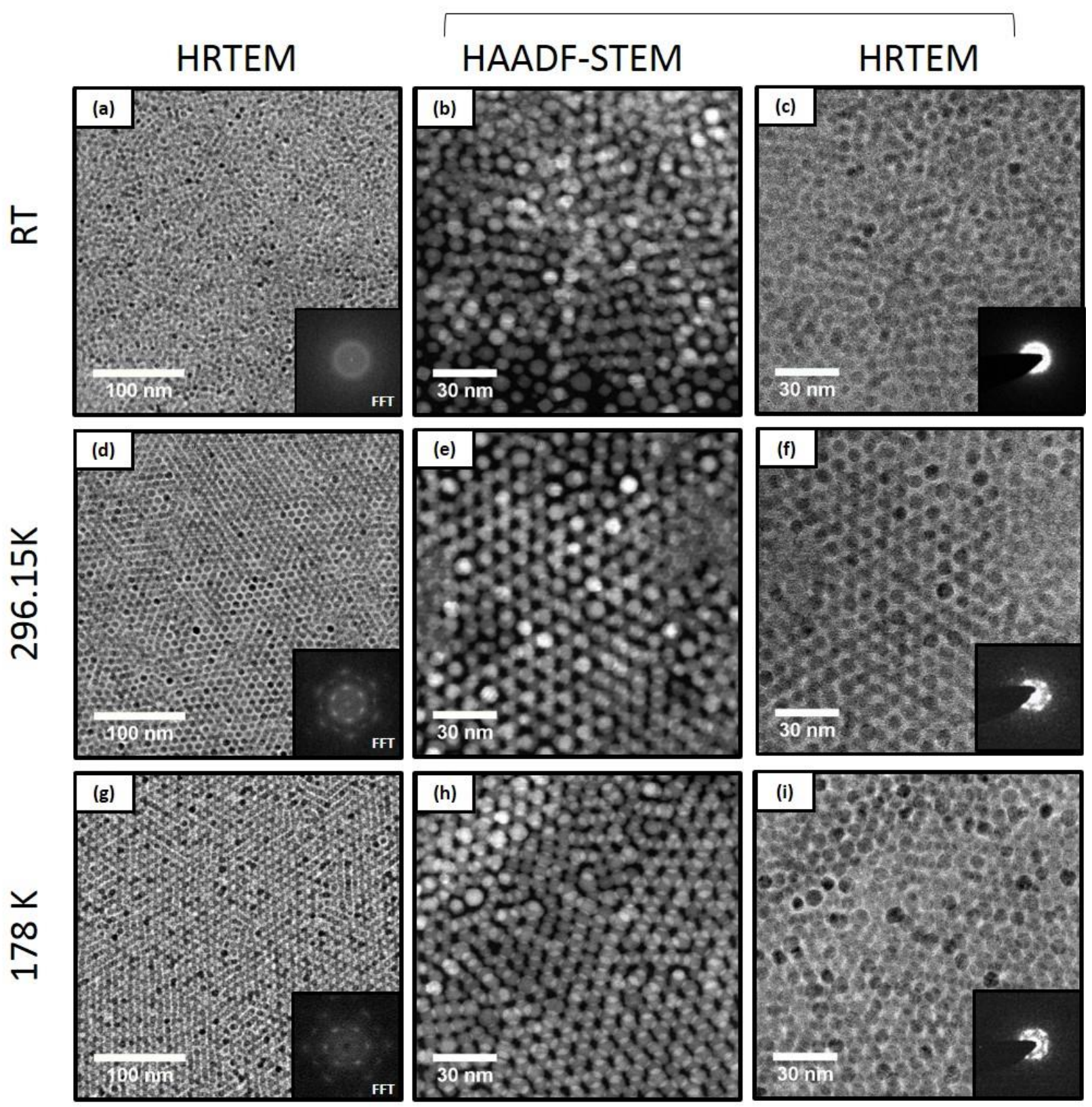

Figure S7. Electron microscopy images of polyhedral $\mathrm{CeO}_{2} \mathrm{NPs}$ prepared by sdw deposition method. (a)-(c) RT, (d)-(f) $269.15 \mathrm{~K}$ and (g)-(i) $178 \mathrm{~K}$. 


\section{Same Areas}
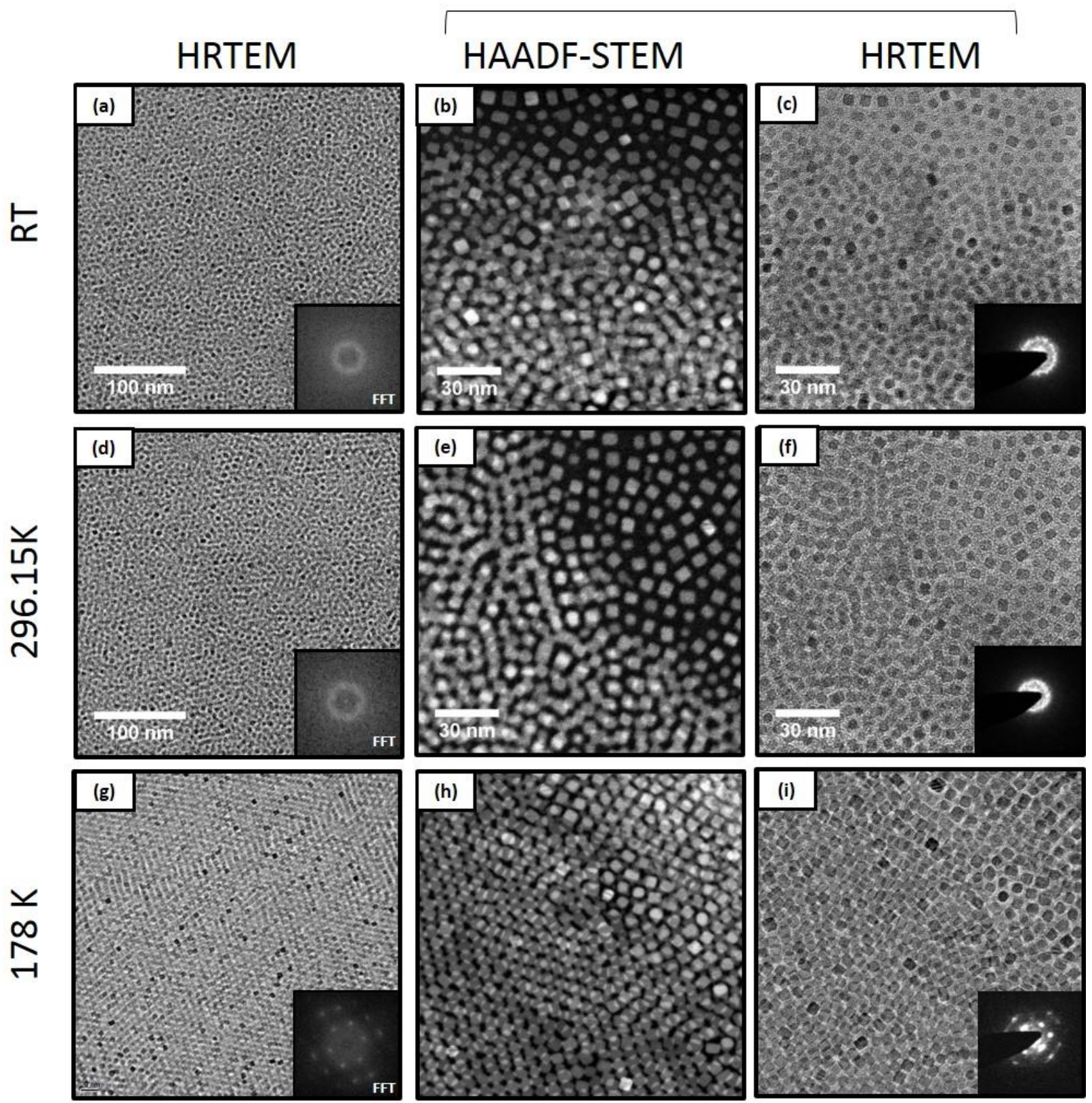

Figure S8. Electron microscopy images of cubic $\mathrm{CeO}_{2} \mathrm{NPs}$ prepared by normal deposition. (a)(c) RT, (d)-(f) $269.15 \mathrm{~K}$ and (g)-(i) $178 \mathrm{~K}$. 


\section{Same Areas}
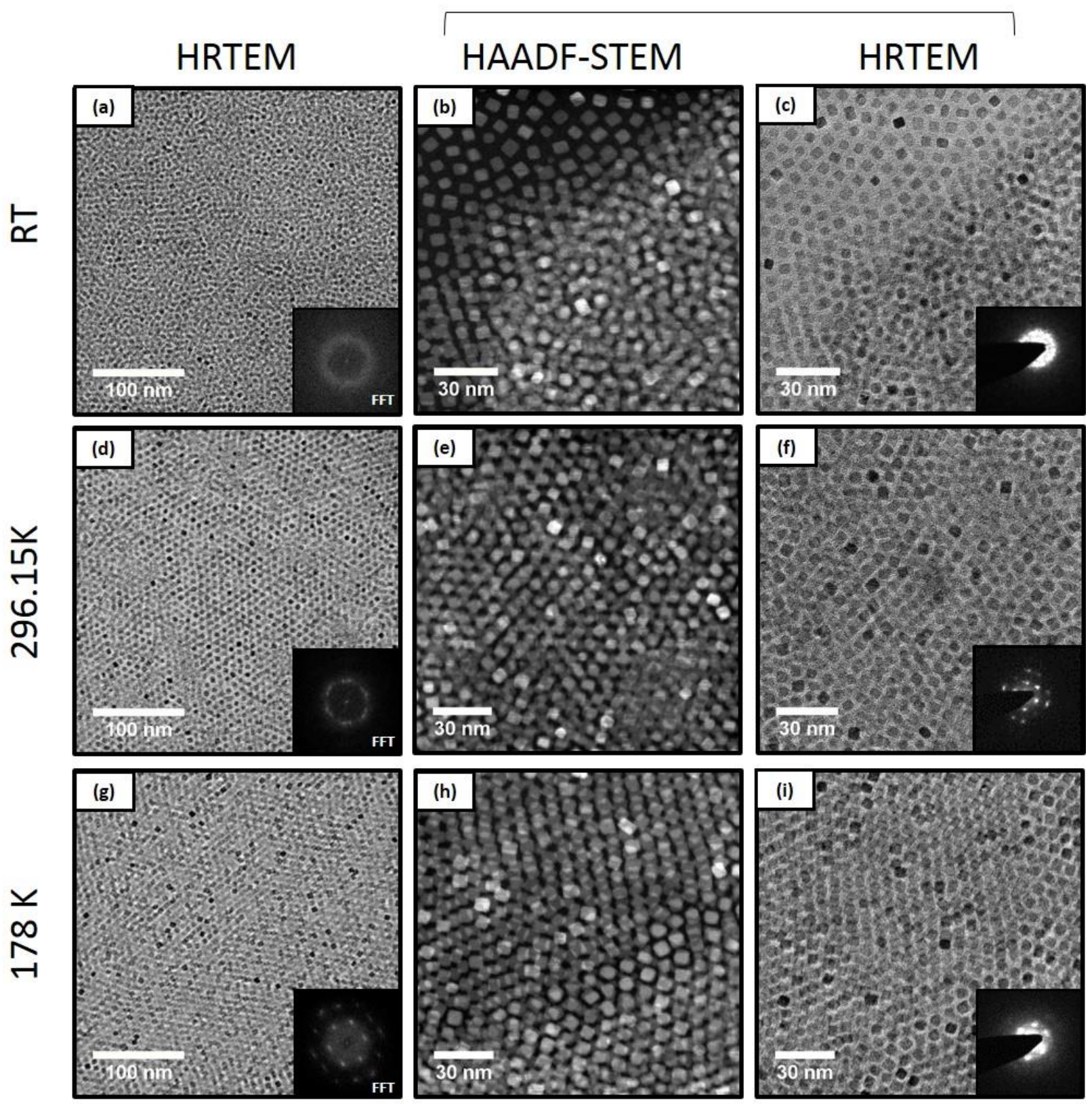

Figure S9. (a) Electron microscopy images of cubic $\mathrm{CeO}_{2} \mathrm{NPs}$ prepared by sdw deposition method. (a)-(c) RT, (d)-(f) $269.15 \mathrm{~K}$ and (g)-(i) $178 \mathrm{~K}$. 

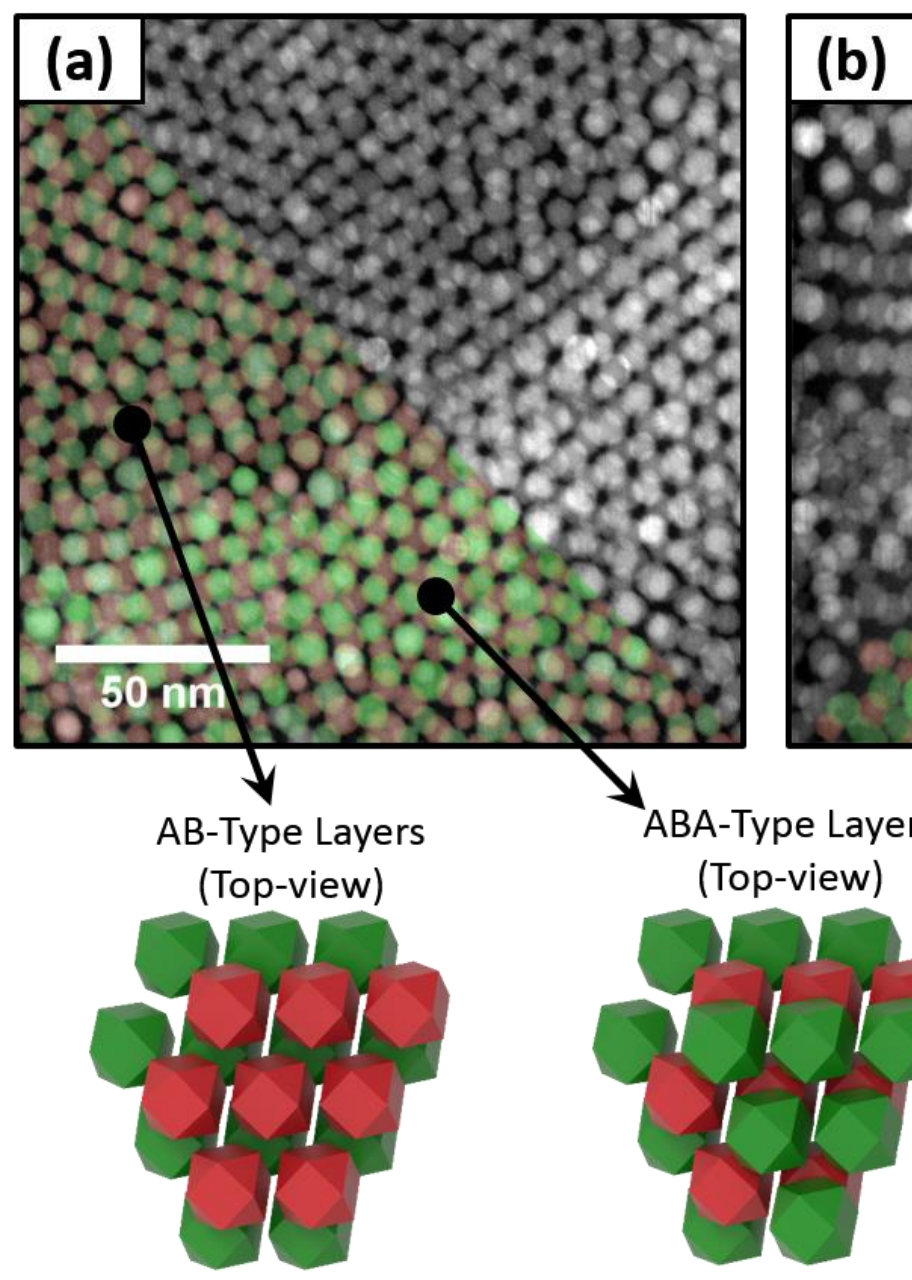

(b)
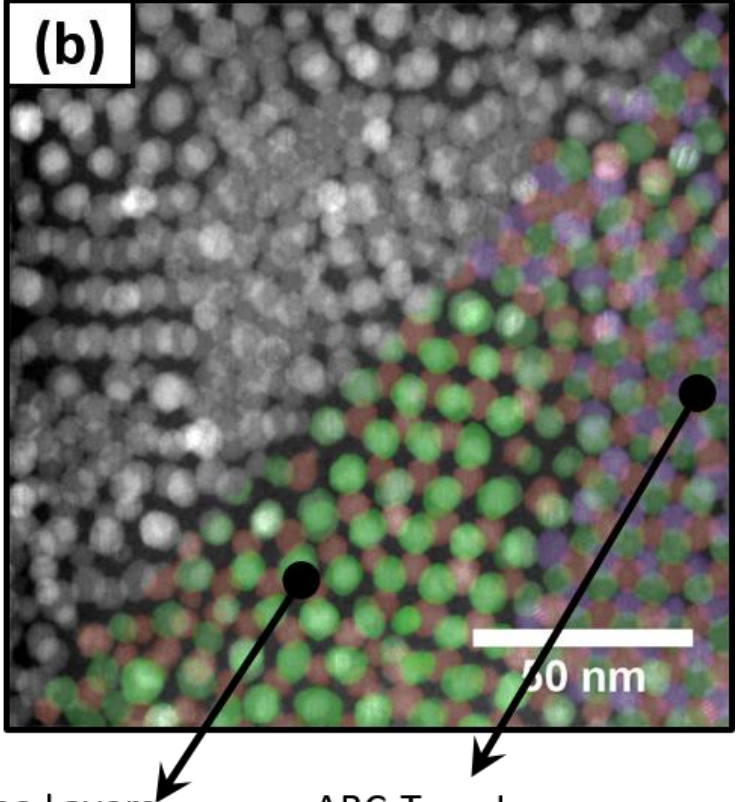

ABA-Type Layers

ABC-Type Layers

\section{(Top-view)}
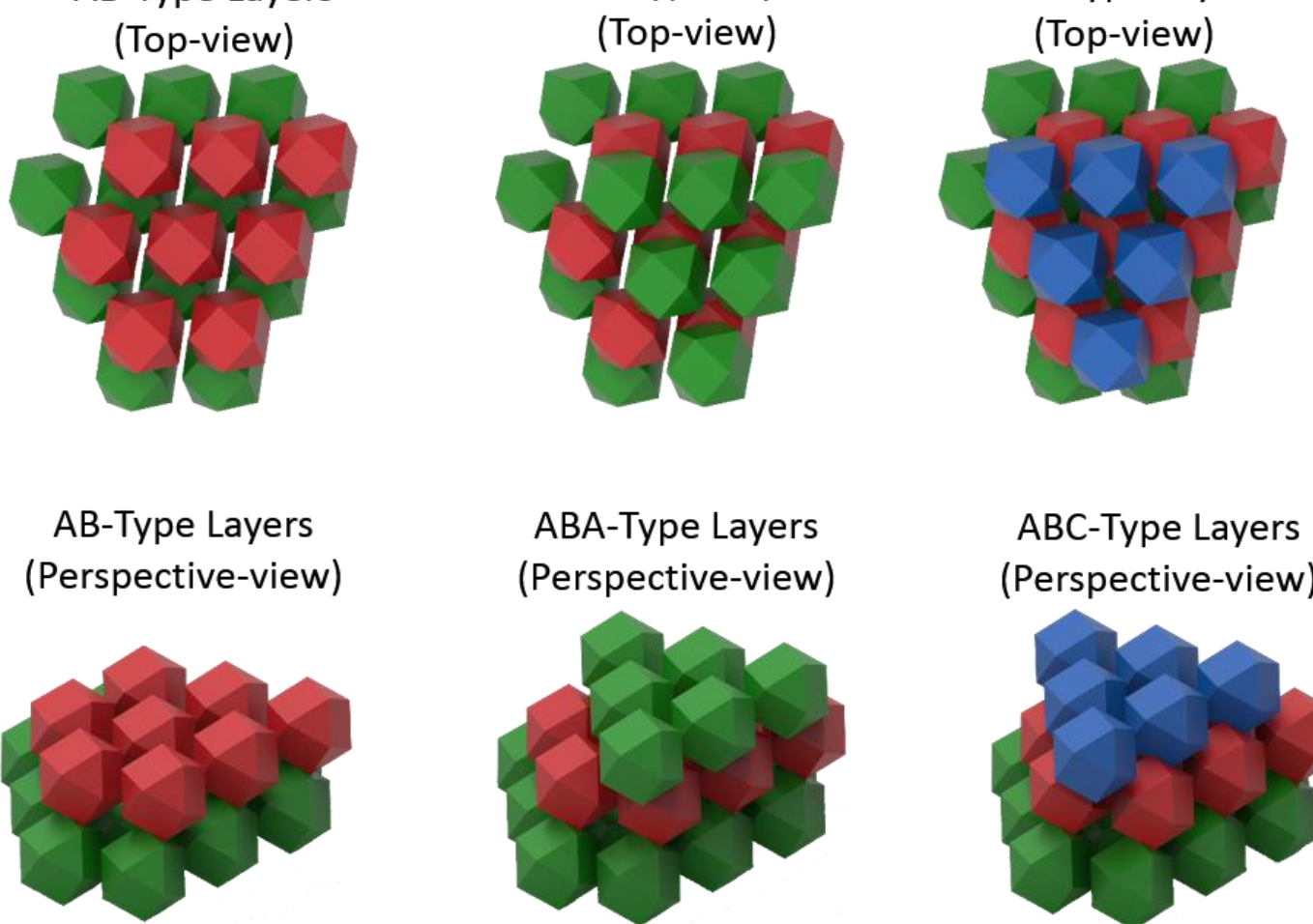

(Perspective-view)
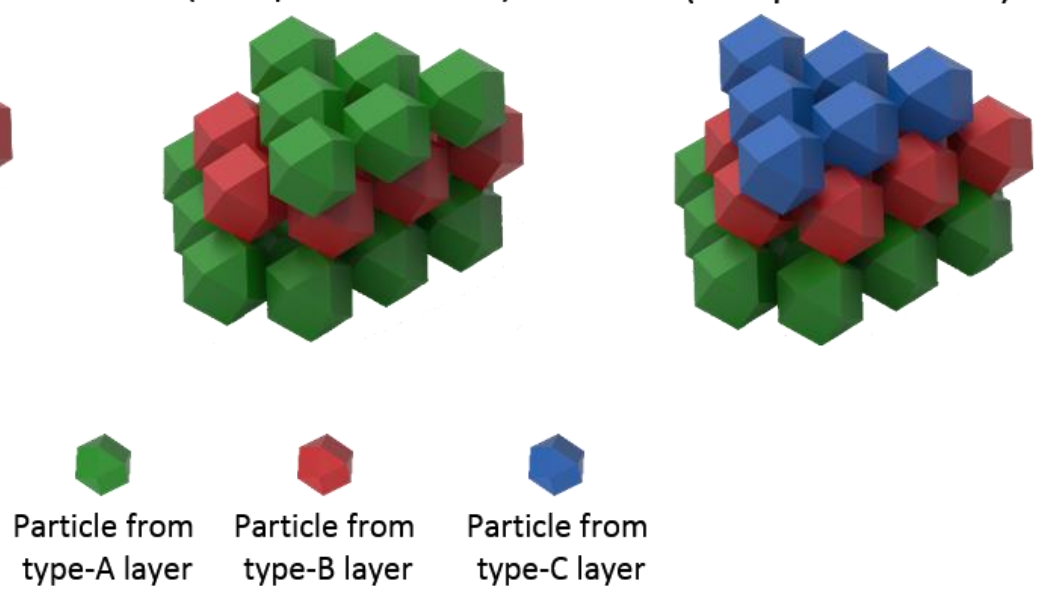

Figure S10. HAADF-STEM images of double layers $(\mathrm{AB}), \mathrm{FCC}(\mathrm{ABC})$ and $\mathrm{HCP}(\mathrm{ABA})$ structures in polyhedral $\mathrm{CeO}_{2} \mathrm{NPs}$ structures. 


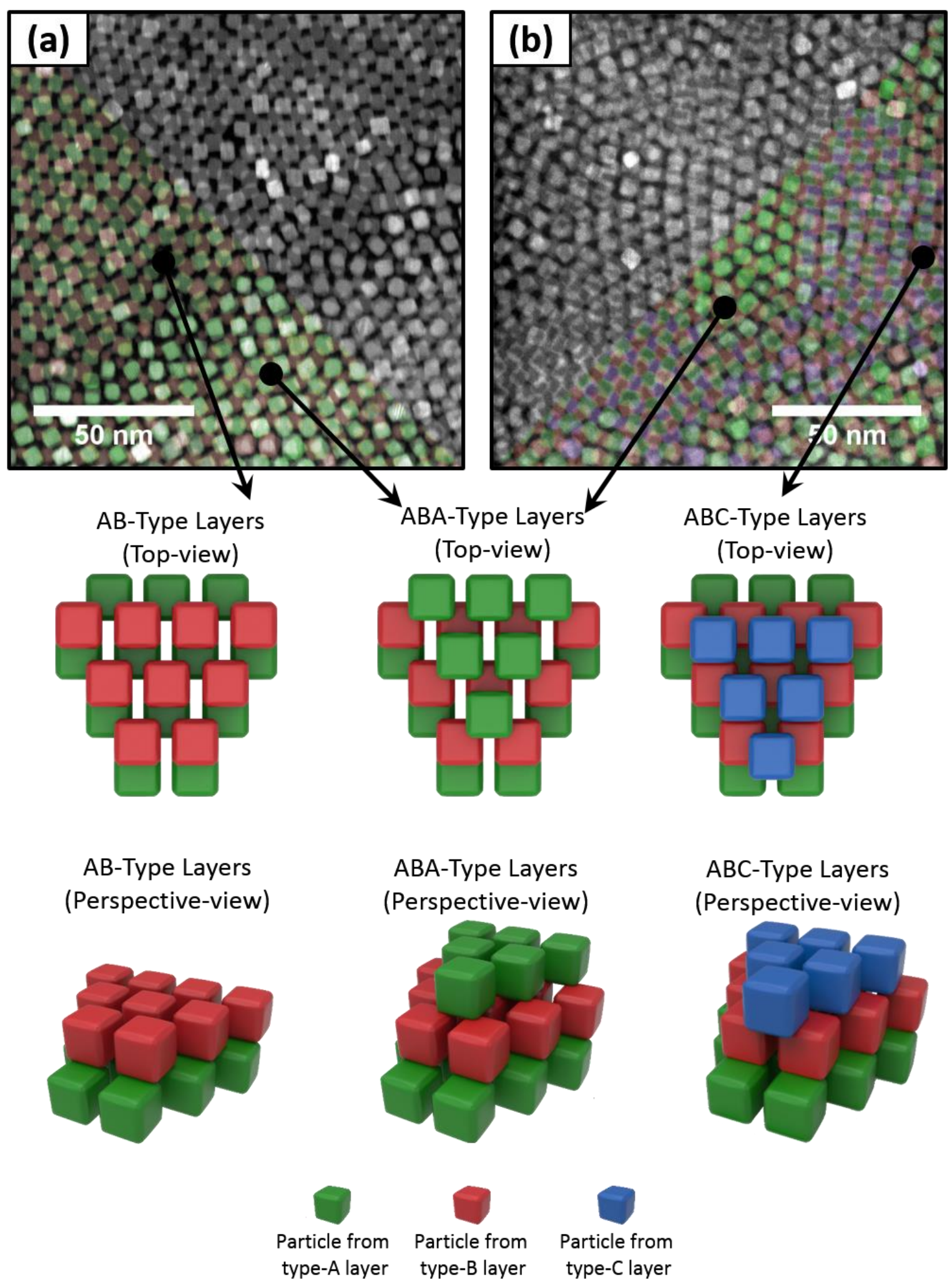

Figure S11. HAADF-STEM images of double layers $(\mathrm{AB}), \mathrm{FCC}(\mathrm{ABC})$ and $\mathrm{HCP}(\mathrm{ABA})$ structures in cubic $\mathrm{CeO}_{2} \mathrm{NPs}$ structures. 

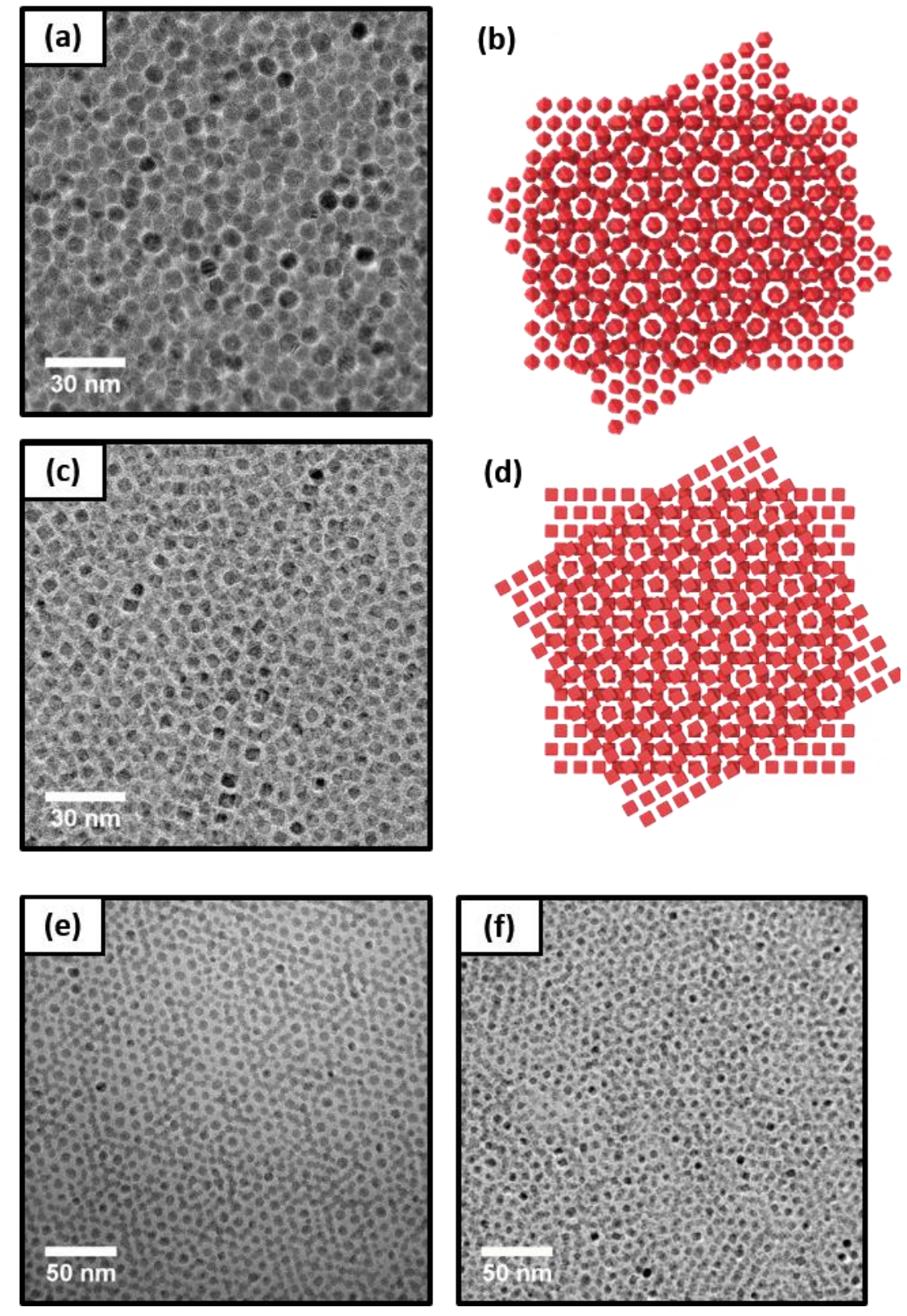

Figure S12. (a) hexagonal non-compact (hnc) packing of polyhedral $\mathrm{CeO}_{2} \mathrm{NPs}$ and (b) arrangement scheme; (c) hexagonal non-compact (hnc) packing of cubic $\mathrm{CeO}_{2} \mathrm{NPs}$ and (d) arrangement scheme. (e) and (f) earlier formation of hexagonal non-compact (hnc) packing of polyhedral and $\mathrm{CeO}_{2}$ NPs, respectively. 


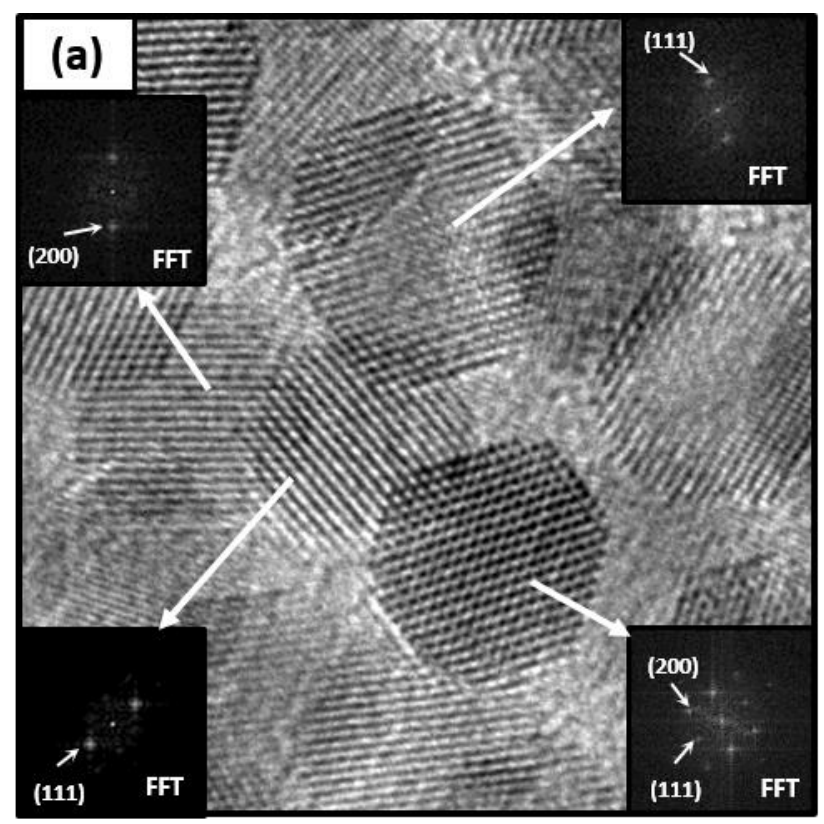

\section{(b)}

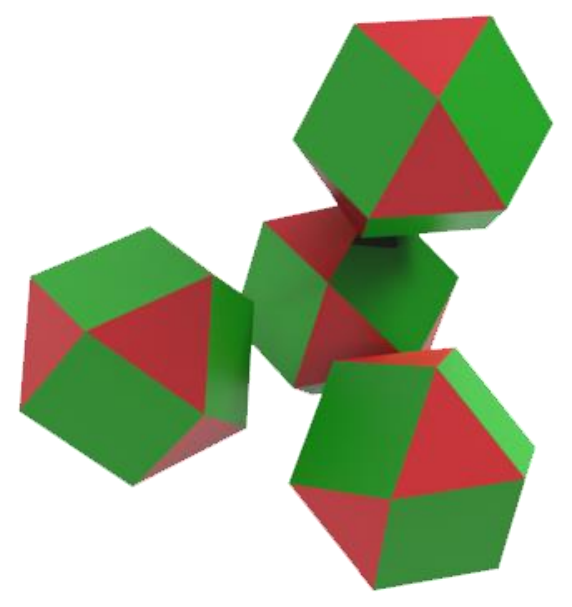

\section{(c)}

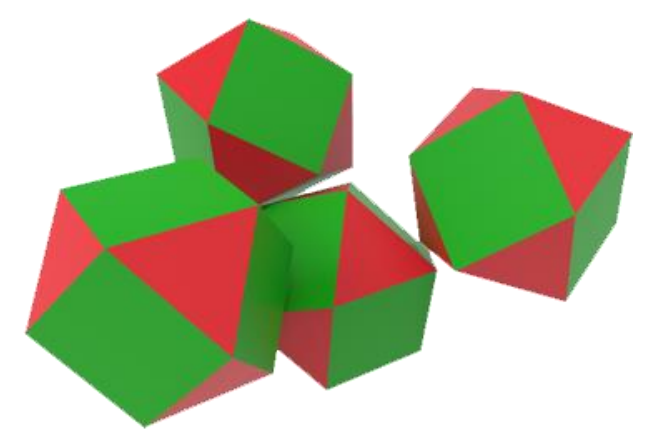

Figure S13. (a) HRTEM image of an organization of 2 layers of polyhedral $\mathrm{CeO}_{2} \mathrm{NPs}$ and its orientation analysis by FFT (inserted). (b) Resulting system of NP orientation from the FFT analysis (Top View) and (c) same structure in perspective view. 


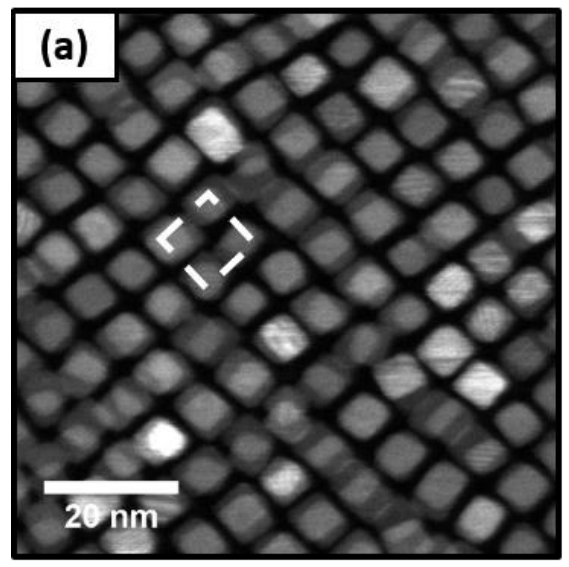

(b)
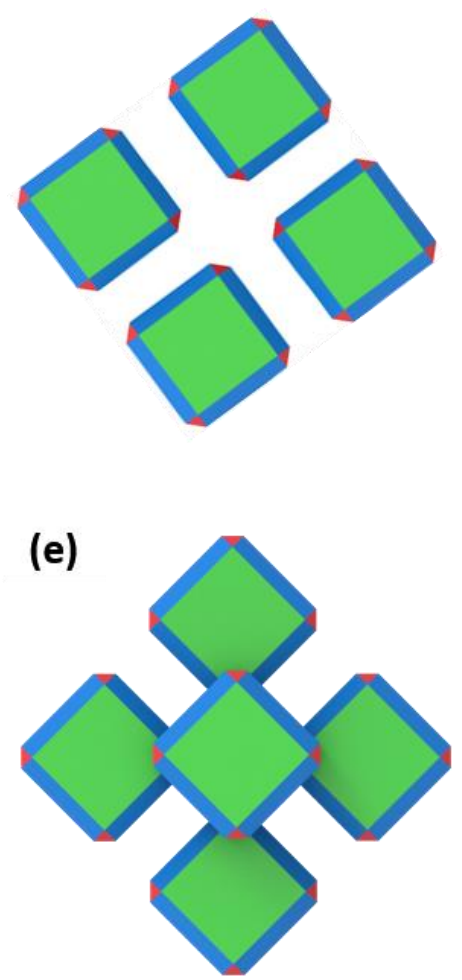

$20 \mathrm{~nm} \times 10 \times 00.2$

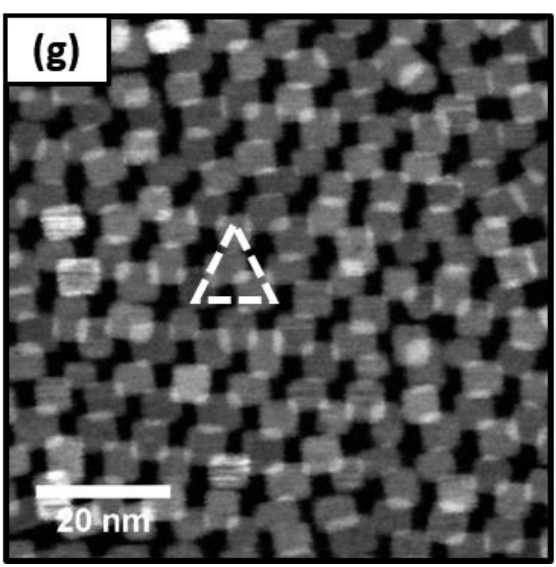

(c)
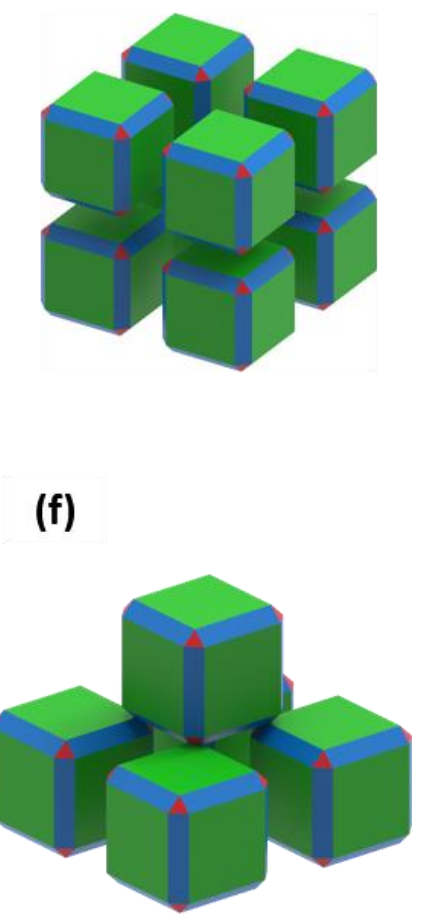

(i)

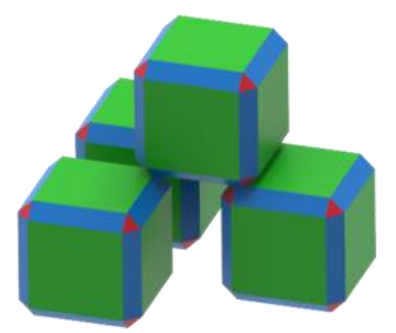

Figure S14. Types of organization of cubic $\mathrm{CeO}_{2} \mathrm{SA}$ (a) HAADF-STEM image of sc structure, (b) schematic in top view and (c) perspective. (d) HAADF-STEM image of double layer (Type 01), (e) schematic in top view and (f) perspective. (g) HAADF-STEM image of double layer (Type 02), (h) schematic in top view and (i) perspective. 


\section{Estimation of the nonretarded Hamaker constant of $\mathrm{CeO}_{2}$ in toluene}

Hamaker constant of the $\mathrm{CeO}_{2}$ in toluene $\left(A_{121}\right)$ was estimated based on the relation:2

$A_{121} \cong\left(\sqrt{A_{11}}-\sqrt{A_{22}}\right)^{2}$

where $A_{11}$ and $A_{22}$ are the Hamaker constants of $\mathrm{CeO}_{2}$ and toluene in vacuum, respectively.

The calculation of the $\mathrm{CeO}_{2}$ Hamaker constant can be performed by using the simplified expression of the Lifshitz theory:2, 3,4,5

$A_{11}=\frac{3}{4} k_{B} T\left(\frac{\varepsilon-1}{\varepsilon+1}\right)^{2}+\frac{3 h v_{e}}{16 \sqrt{2}} \frac{\left(n^{2}-1\right)^{2}}{\left(n^{2}+1\right)^{3 / 2}}$

where $k_{B}$ is the Boltzmann constant, $\mathrm{T}$ is temperature, $\varepsilon$ is the static dielectric constant for $\mathrm{CeO}_{2}, h$ is the Planck constant, $v_{e}$ is the maximum electronic ultraviolet absorption frequency and $n$ is the absolute refractive index. Estimations of $A_{11}$ at lower temperatures were performed by considering changes in static dielectric constant and small variations of the absolute refractive index. ${ }^{6}$

The Hamaker constant of the toluene $\left(A_{22}\right)$ in vacuum was estimated based on the toluene surface tension $\left(\gamma, 28.510^{-3} \mathrm{Nm}^{-1}\right)^{7}$, derived from the pairwise summation theory: ${ }^{2}$

$A_{22}=24 \pi \gamma d_{0}^{2}$

where $d_{0}$ is the distance between molecules neighbors and can be approached to a"cut off" distance substantially less than the intermolecular center-to-center distance ${ }^{2,8,9}$, which value of $1.6510^{-10}$ $\mathrm{m}$ is considered a good approximation, resulting in a reliable fitting between calculated and experimental values of Hamaker constant of liquids. ${ }^{2}$ For toluene Hamaker constant at lower temperatures, surface tensions were calculated by using the equation derived from statistical mechanics proposed by Escobedo et al. ${ }^{10}$

The determined Hamaker constants of $\mathrm{CeO}_{2}$ in toluene were $4.0910^{-21} \mathrm{~J}, 2.6210^{-21} \mathrm{~J}$ and $2.610^{-}$ $22 \mathrm{~J}$ at RT, $269.15 \mathrm{~K}$ and $178 \mathrm{~K}$, respectively. 


\section{Rough estimation of the total energy potentials between $\mathrm{CeO}_{2}$ nanoparticles in toluene}

Total energy potentials were calculated based on the sum of attractive (van de Waals) and repulsive potentials (osmotic) for a single NP in each structure, according to the coordination number and considering only the closest NPs to the studied one ${ }^{11}$.

\section{(1) Estimation of the van der Waals forces $\left(\Phi_{v d W}\right)$}

The van der Waals forces between NPs were calculated by the Hamaker pairwise summation ${ }^{2}, 3,12$, ${ }^{13}$, which has provided reliable estimation of $\Phi_{v d W}$ for NP systems ${ }^{2,14,15,16}$.

\section{(a) Van de Waals forces for Polyhedral NPs}

Polyhedral NPs were considered to have an approximately spherical shape (isotropic interactions between NPs). Consequently, the $\Phi_{v d W}$ estimation for each pair of particles can be obtained by the expression: 3,13

$$
\Phi_{v d W}=-\frac{A_{121}}{12}\left[\frac{4 r^{2}}{z^{2}-4 r^{2}}+\frac{4 r^{2}}{z^{2}}+2 \ln \left(1-\frac{4 r^{2}}{z^{2}}\right)\right]
$$

where $d$ is the distance between two exposed facets, $\mathrm{z}$ the center-to-center interparticle distance and $r$ the NP radius.

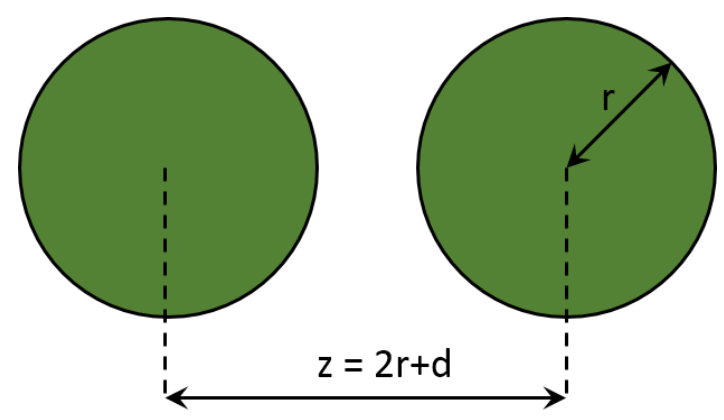

(b) Van de Waals forces for cubic NPs

The estimation of van der Waals forces for cubic NPs were calculated based on the expressions developed by Derocco et al. ${ }^{3,17}$. Since the cubic NP shape is not isotropic, van der Waals forces depend on the particle orientation. In this study, the face-to-face and edgeto-edge orientations are the most important to this study. 
- Face-to-face van der Waals interaction $\left(\Phi_{v d W, f-f}\right)$

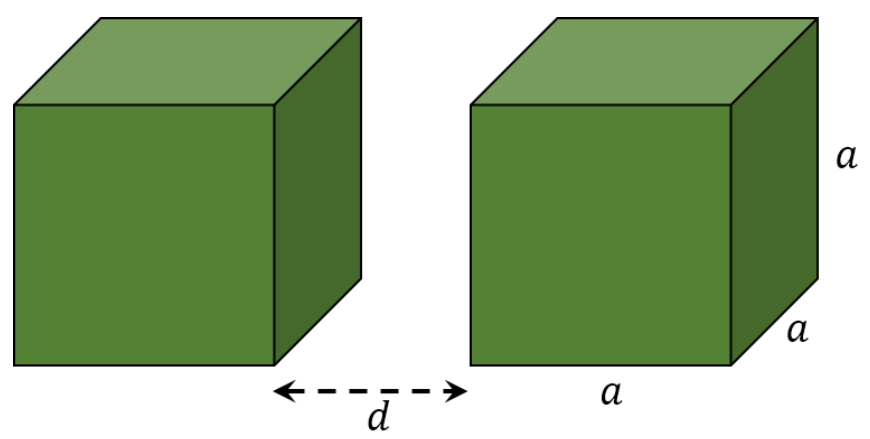

Face-to-face van der Waals interaction can be calculated as a function of interparticle distance $(d)$ and particle edge size $(a)$, as follows:

$\Phi_{v d W, f-f}=-\left.\frac{A_{121}}{\pi^{2}} K_{p p}(x)\right|_{d+a, d+a^{\prime}} ^{d+2 a, d}$

where,

$\left.K_{p p}(x)\right|_{d+a, d+a^{\prime}} ^{d+2 a, d}=K_{p p}(d+2 a)-2 K_{p p}(d+a)+K_{p p}(d)$

and,

$$
\begin{aligned}
K_{p p}(x)=\frac{1}{4} \ln & \left(\frac{\left(x^{2}+a^{2}\right)^{2}}{x^{4}+2 a^{2} x^{2}}\right)+\left(\frac{x^{2}-a^{2}}{4 a x}\right) \tan ^{-1}\left(\frac{a}{x}\right) \\
+ & \left(\frac{x^{2}-a^{2}}{4 b a}\right) \tan ^{-1}\left(\frac{a}{x}\right)+\frac{x(2)^{3 / 2}}{6 a} \tan ^{-1}\left[\frac{d}{a(2)^{1 / 2}}\right] \\
+ & 2\left(\frac{1}{6 x^{2}}+\frac{1}{6 a^{2}}\right) a\left(x^{2}+a^{2}\right)^{1 / 2} \tan ^{-1}\left[\frac{a}{\left(x^{2}+a^{2}\right)^{1 / 2}}\right]
\end{aligned}
$$


- Edge-to-edge van der Waals interaction $\left(\Phi_{v d W, e-e}\right)$

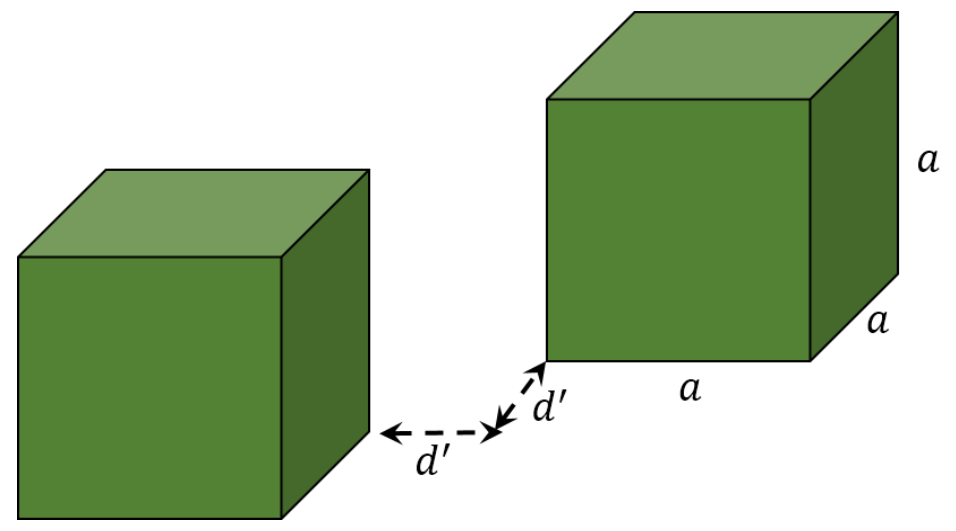

Edge-to-edge van der Waals interaction can be integrated, as follows:

$\Phi_{v d W, e-e}=-\left.\frac{A_{121}}{\pi^{2}} K_{s p}(x)\right|_{d \prime+c, d \prime+c^{\prime}} ^{d \prime+2 c, d \prime}$

where

$\left.K_{S P}\left(x ; d^{\prime}\right)\right|_{d^{\prime}+a, d^{\prime}+a^{\prime}} ^{d \prime+2 a, d^{\prime}}=K_{s p}(x+2 a)-2 K_{s p}(x+a)+K_{s p}(x)$

and,

$$
\begin{aligned}
K_{S P}(x) & =\frac{1}{8}\left(\frac{d^{2}+x^{2}}{2 a^{2}+x^{2}}\right)+\frac{1}{8}\left(\frac{x}{d \prime}-\frac{d}{x}\right) \tan ^{-1}\left(\frac{d \prime}{x}\right) \\
& +\frac{\left(a^{2}+d^{\prime 2}\right)^{3 / 2} x}{12 a^{2} d^{\prime 2}} \tan ^{-1} \frac{x}{\left(a^{2}+d^{\prime 2}\right)^{1 / 2}}+\frac{a\left(d^{2}+x^{2}\right)^{1 / 2}}{12}\left(\frac{1}{d^{2}}+\frac{1}{x^{2}}\right) \tan ^{-1} \frac{a}{\left(a^{2}+x^{2}\right)^{1 / 2}} \\
& +\frac{a\left(c^{2}+x^{2}\right)^{1 / 2}}{12}\left(\frac{1}{d^{2}}+\frac{1}{x^{2}}\right) \frac{d}{\left(a^{2}+x^{2}\right)^{1 / 2}}
\end{aligned}
$$

Additionally, inasmuch as the distance between particles gets closer, edge-to-edge, face-to-face and vertice-vertice interactions converge to that seen between closely approaching spheres. ${ }^{3}$ 


\section{(2) Estimation of the osmotic potentials $\left(\Phi_{\text {osm }}\right)$}

Osmotic potential energies $\left(\Phi_{\text {osm }}\right)$ were calculated based on the expressions developed by Napper et al. ${ }^{18,19}$ and Vicent et al.:20

$$
\begin{aligned}
& \Phi_{o s m}=\frac{4 k_{B} T \phi^{2}}{v_{\text {sol }}}\left(\frac{1}{2}-\chi\right) H_{1}, \text { for } l<d<2 l \\
& \Phi_{o s m}=\frac{2 k_{B} T \phi^{2}}{v_{\text {sol }}}\left(\frac{1}{2}-\chi\right) H_{2}, \text { for } d<l
\end{aligned}
$$

where $\phi$ is the volume fraction profile, $v_{\text {sol }}$ the volume of the solvent (toluene), $\rho$ and $M W$ the density and molecular weight of the ligand (oleic acid), respectively, and $\chi$ is the Flory-Huggins interaction parameter. $H_{1}$ and $H_{2}$ are geometric parameters, according to the shape of interacting bodies.

For sphere-sphere separation:

$H_{1}=\pi\left(1-\frac{d-2 R}{2 l}\right)^{2}$

and

$H_{2}=2 \pi\left[l^{2}\left(\frac{d-2 R}{2 l}-\frac{1}{4}-\ln \left(\frac{d-2 r}{l}\right)\right)\right] ;$

For plate-plate separation:

$H_{1}=\frac{1}{l}\left(1-\frac{d}{2 l}\right)$

and

$H_{1}=\frac{1}{d}$

As a matter of comparison, the size of nanoparticles was fixed in $7 \mathrm{~nm}$ and it was assumed that the NPs had shapes proportional to that shown in Figures S4 and S5.

The volume fraction profile can be determinate in ligand covered particles in a good solvents, where the ligand (oleate group) is fully extended, and compared to their thermal analysis (for organic covered quantification). Based on previous studies, we considered full covered ligand NPs in our calculations. ${ }^{21}$ 
The Flory-Huggins interaction parameter represents the interaction of the oleate groups with the solvent molecules and the oleate-oleate interactions, i.e., degree of solubility of the ligand $(0<\chi$ $<1)$. The value of 0.5 represents the boundary between a good solvent $(\chi<0.5)$ and a poor solvent $(\chi>0.5)$. When $\chi>0.5, \Phi_{\text {osm }}$ becomes negative, resulting in NP aggregation. Because the oleic acid is soluble in organic solvents, it was used as the value of 0 for $\chi$ at RT ${ }^{22}$. 

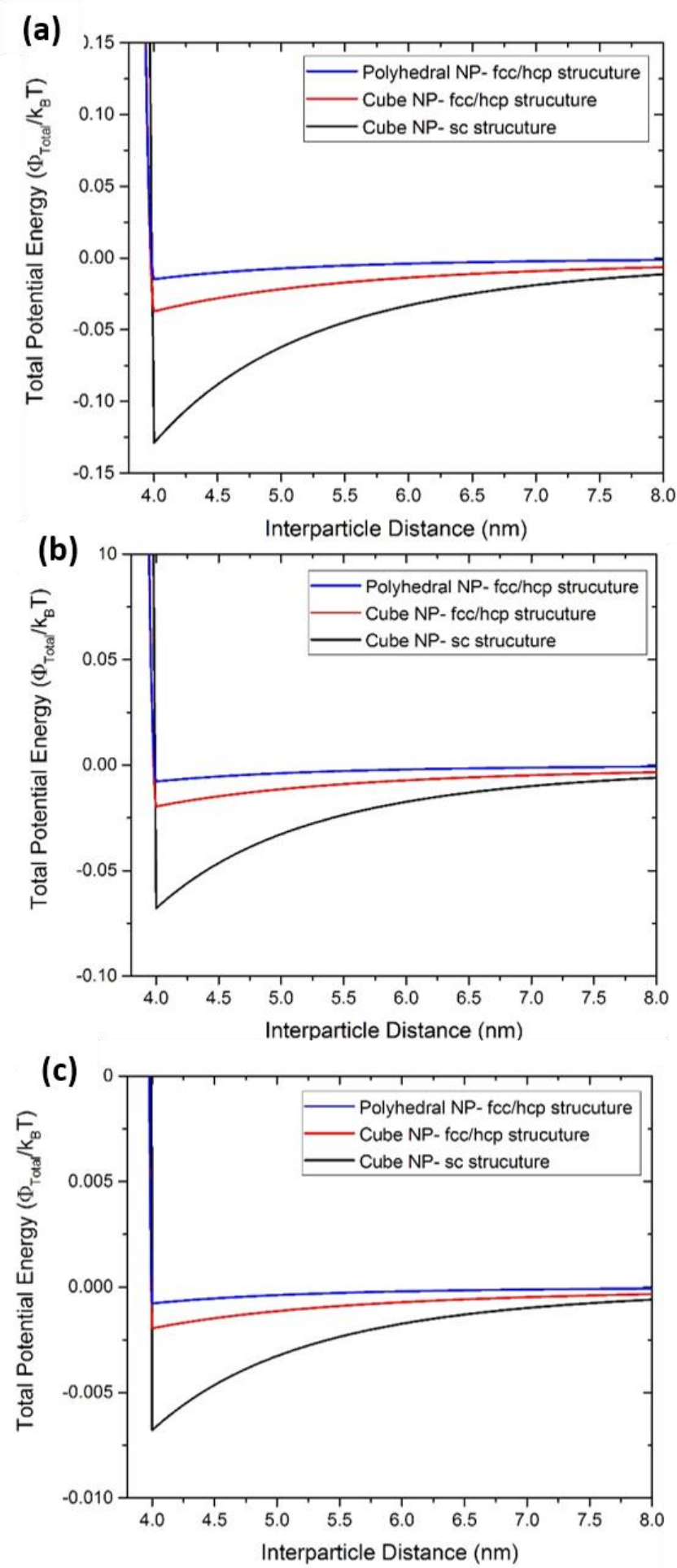

Figure S15. Total potential energy for polyhedral and cubic NPs according to interparticle distance. (a) RT, (b) $269.15 \mathrm{~K}$ and (c) $178 \mathrm{~K}$. 

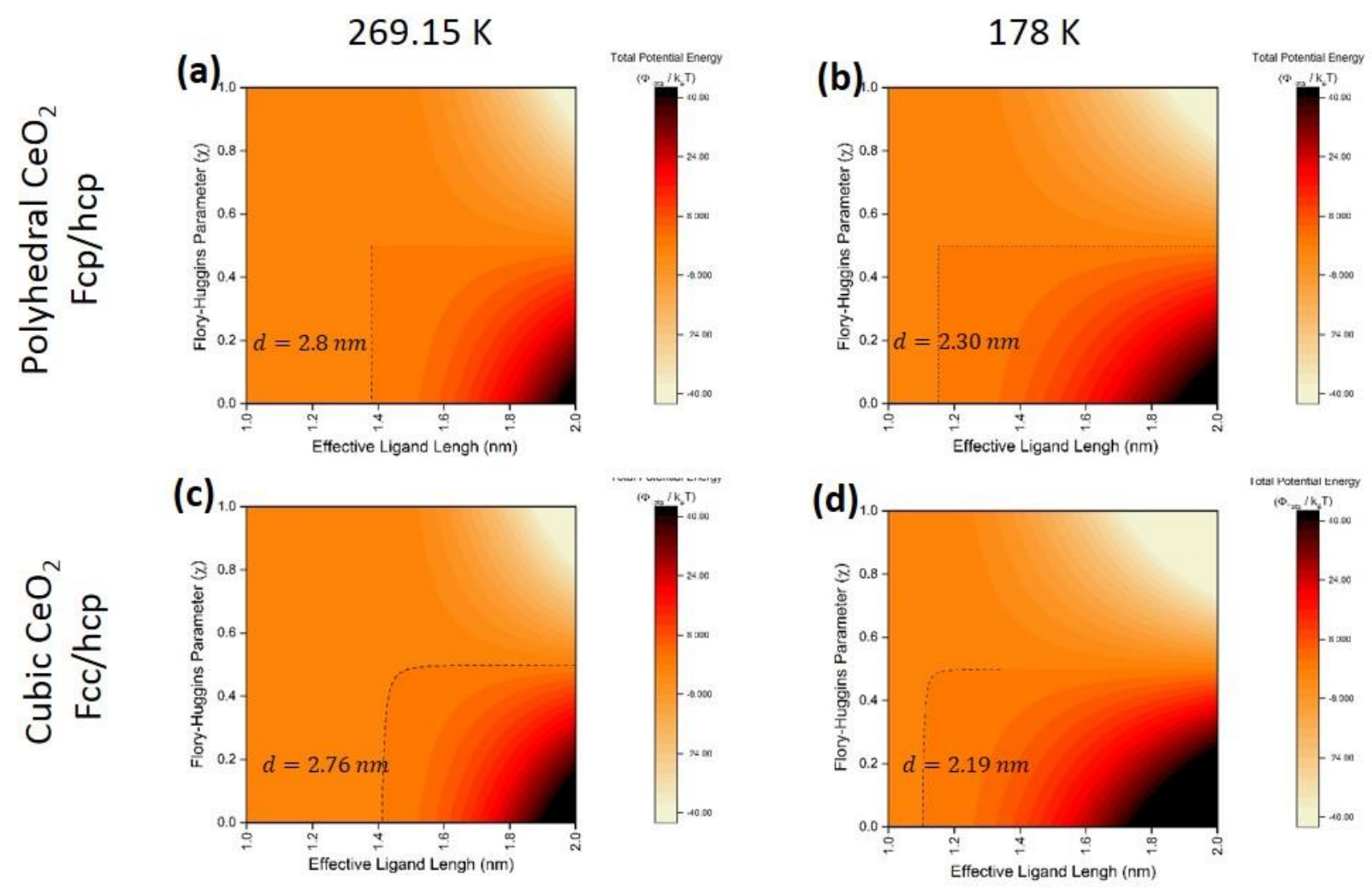

Figure S16. Total potential energy maps of (a)-(b) polyhedral $\mathrm{CeO}_{2} \mathrm{NPs}$ of fcc/hcp and (c)-(d) cubic $\mathrm{CeO}_{2} \mathrm{NPs}$ of fcc/hcp strucutures according to the ligand effective size and Flory-Huggins parameter at $269.15 \mathrm{~K}$ and $178 \mathrm{~K}$. For each graph, the mean interparticle distance was used (d) here we plot the values shown in Table 1, wherein mean values are highlighted in each graph. 
(a)

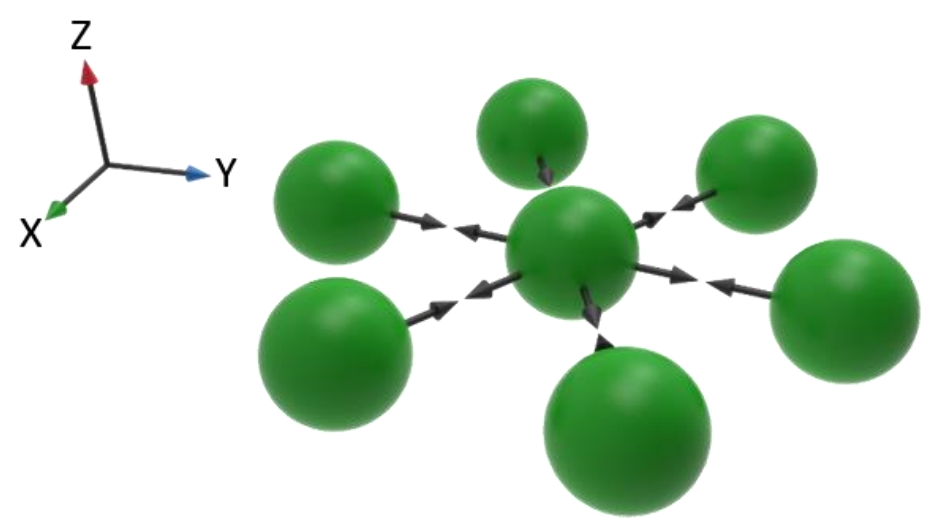

(b)

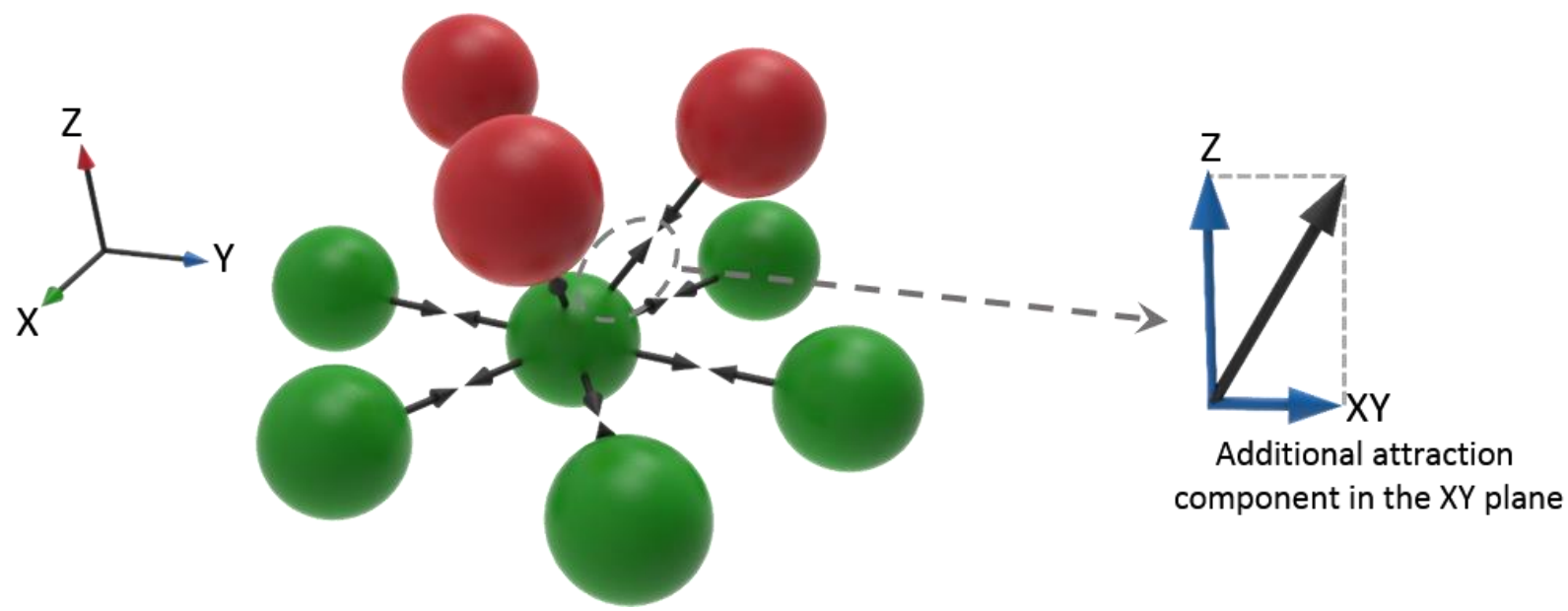

Figure S17. Illustration of the interparticle forces in (a) monolayer and (b) bilayer system of NPs. 


\section{References}

1. Faghri, A.; Zhang, Y.; Howell, J. R. Advanced Heat and Mass Transfer; Global Digital Press2010.

2. Israelachvili, J. N. Intermolecular and Surface Forces: Revised Third Edition; Elsevier Science2011.

3. Parsegian, V. A. Van der Waals Forces: A Handbookfor Biologists, Chemists, Engineers, and Physicists; Cambridge University Press2005.

4. Lifshitz, E. M. The theory of molecular attractive forces between solids. Soviet Physics Jetp-Ussr 1956, 2 (1), 73-83.

5. Dzyaloshinskii, I. E.; Lifshitz, E. M.; Pitaevskii, L. P. The general theory of van der Waals forces. Advances in Physics 1961, 10 (38), 165-209.

6. Walkenhorst, A.; Schmitt, M.; Adrian, H.; Petersen, K. $\mathrm{CeO}_{2}$ - An alternative insula tor material for superconducting field-effect devices. Applied Physics Letters 1994, 64 (14), 18711873.

7. Lide, D. R. CRC Handbook of Chemistry and Physics, 85th Edition; Taylor \& Francis2004.

8. Israelachvili, J. N. van der Waals dispersion force contribution to works of adhesion and contact angles on the basis of macroscopic theory. Journal of the Chemical Society Faraday Transactions II 1973, 69, 1729-38.

9. Hough, D. B.; White, L. R. The calculation of Hamaker constants from Lifshitz theory with applications to wetting phenomena. Advances in Colloid and Interface Science 1980, 14 (1), 3-41. 10. Escobedo, J.; Mansoori, G. A. Surface tension prediction for pure fluids. Aiche Journal 1996, 42 (5), 1425-1433.

11. Chan, H.; Demortiere, A.; Vukovic, L.; Kral, P.; Petit, C. Colloidal Nanocube Supercrystals Stabilized by Multipolar Coulombic Coupling. Acs Nano 2012, 6 (5), 4203-4213.

12. Verwey, E. J. W.; Overbeek, J. T. G.; Overbeek, J. T. G. Theory of the Stability of Lyophobic Colloids; New York; Leiden printed1948.

13. Verwey, E. J. W.; Overbeek, J. T. G.; Overbeek, J. T. G. Theory of the Stability of Lyophobic Colloids; Dover Publications1999.

14. Wang, C. Y.; Siu, C.; Zhang, J.; Fang, J. Y. Understanding the forces acting in selfassembly and the implications for constructing three-dimensional (3D) supercrystals. Nano Res. 2015, 8 (8), 2445-2466.

15. Goubet, N.; Richardi, J.; Albouy, P.-A.; Pileni, M.-P. Which Forces Control Supracrystal Nucleation in Organic Media? Advanced Functional Materials 2011, 21 (14), 2693-2704.

16. Bishop, K. J. M.; Wilmer, C. E.; Soh, S.; Grzybowski, B. A. Nanoscale Forces and Their Uses in Self-Assembly. Small 2009, 5 (14), 1600-1630.

17. Derocco, A. G.; Hoover, W. G. On the interaction of colloidal particles. Proc. Natl. Acad. Sci. U. S. A. 1960, 46 (8), 1057-1065.

18. Napper, D. H. Steric stabilization. Journal of Colloid and Interface Science 1977, 58 (2), 390-407.

19. Evans, R.; Napper, D. H. Pertubation method for incorporating concentration-dependence of Flory-Huggins parameter into theory of steric stabilization. Journal of the Chemical SocietyFaraday Transactions I 1977, 73, 1377-1385.

20. Vincent, B.; Edwards, J.; Emmett, S.; Jones, A. Depletion flocculation in dispersions of sterically-stabilised particles ("soft spheres"). Colloids and Surfaces 1986, 18 (2-4), 261-281. 
21. Cordeiro, M. A. L.; Weng, W.; Stroppa, D. G.; Kiely, C. J.; Leite, E. R. High Resolution Electron Microscopy Study of Nanocubes and Polyhedral Nanocrystals of Cerium(IV) Oxide. Chemistry of Materials 2013, 25 (10), 2028-2034.

22. Kolb, D. K.; Brown, J. B. Low Temperature Solubilities of Fatty Acids in Selected Organic Solvents. Journal of the American Oil Chemists Society 1955, 32 (6), 357-361. 